\title{
Levels of selected persistent organic pollutants in blood from delivering women in seven selected areas of São Paulo State, Brazil
}

Cibele V. C. Rudge ${ }^{\text {*ab }}$, Torkjel Sandanger ${ }^{\text {bc }}$,Halina B. Röllin ${ }^{\text {de }}$, Iracema M. P. Calderon ${ }^{a}$, Gustavo Volpato ${ }^{a}$, João L. P. Silva ${ }^{\dagger}$, Geraldo Duarte ${ }^{9}$, Corintio M Neto ${ }^{h}$, Nelson Sass ${ }^{i j}$, Mary U Nakamura ${ }^{j}$, Jon $\varnothing$. Odland ${ }^{b}$, Marilza V. C. Rudge ${ }^{a}$

a Univ. Estadual Paulista, UNESP, Brazil

${ }^{b}$ Institute of Community Medicine, University of Tromsø, Tromsø, Norway

${ }^{c}$ Norwegian Institute for Air Research, Tromsø, Norway

${ }^{d}$ South African Medical Research Council, Johannesburg, South Africa

${ }^{e}$ School of Health Systems \& Public Health, University of Pretoria, Pretoria, South Africa

${ }^{f}$ Univ. de Campinas, UNICAMP, Brazil

${ }^{g}$ Univ. São Paulo, USP-Ribeirão Preto, Brazil

${ }^{h}$ Hospital and Maternity Leonor Mendes de Barros, São Paulo, Brazil

'Maternity Vila Nova Cachoeirinha, São Paulo, Brazil

${ }^{j}$ Univ. Federal of São Paulo, UNIFESP, Brazil

*Corresponding author: Univ. Estadual Paulista, UNESP, Brazil

Address: R. General Telles, 1396. Botucatu - SP-Brazil

Zip Code: 18602-120. E-mail: cirudge@yahoo.com.br

Telephone/ Fax: +55 14 3882-2004 


\begin{abstract}
Persistent organic pollutants (POPs) present in the living environment are thought to have detrimental health effects on the population, with pregnant women and the developing foetus being at highest risk. We report on the levels of selected POPs in maternal blood of 155 delivering women residing in seven regions within the São Paulo State, Brazil.
\end{abstract}

The following selected POPs were measured in the maternal whole blood: 12 polychlorinated biphenyls (PCBs) congeners (IUPAC No. 99,101,118,138, $153,156,163,170,180,183,187,194)$; dichlordiphenyltrichloroethane $p, p$ '-DDT, diphenyldichloroethylene $p, p^{\prime}-\mathrm{DDE}$ and other pesticides such as hexachlorocyclohexanes $(\alpha-\mathrm{HCH}, \beta-\mathrm{HCH}, \gamma-\mathrm{HCH})$, hexachlorobenzene $(\mathrm{HCB})$, chlordanes (t-CD and c-CD, oxy-chlordane), nanochlors (t-NC and c-NC).

Statistical comparisons between regions were performed only on compounds having levels above LOD in $70 \%$ of the samples. PCB118 congener was found to be highest in the industrial site (mean $4.97 \mathrm{ng} / \mathrm{g}$ lipids); PCB138 congener concentration was highest in the Urban 3 site (mean $4.27 \mathrm{ng} / \mathrm{g}$ lipids) and congener PCB153 was highest in the industrial and Urban 3 sites with mean concentration of $7.2 \mathrm{ng} / \mathrm{g}$ lipids and $5.89 \mathrm{ng} / \mathrm{g}$ lipids respectively. Large differences in levels of $p, p^{\prime}-\mathrm{DDE}$ between regions were observed with the Urban 3 and industrial sites having the highest concentrations of $645 \mathrm{ng} / \mathrm{g}$ lipids and 417 $\mathrm{ng} / \mathrm{g}$ lipids, respectively; $\beta-\mathrm{HCH}$ was found to be highest in the Rural 1 site; the $\gamma$ $\mathrm{HCH}$ in Rural 1 and industrial; the HCB in the Rural 1 and industrial sites and oxy-chlordane and t-NC in the Rural 2 sites. An association between levels of some contaminants and maternal age and parity was also found.

\title{
Key-words:
}

Pesticides exposure, delivering women, human blood, São Paulo State, Brazil 


\section{Introduction}

Worldwide, concern is growing about the presence of persistent organic pollutants (POPs) in the living environment and their possible negative impacts both on the environment and on human health. These man-made chemicals are highly resistant to biodegradation and have high affinities for bioaccumulation and biomagnifications, both in the environment and in living organisms, including humans. A number of human studies have shown POP exposure effects on neurological development; thyroid, estrogen, and immune function; and cancer promotion. (Brouwer et al., 1998; Patandin et al., 1999; Porta et al., 2008; RibasFito et al.,2001; Snedeker, 2001; Tryphonas, 1998; Wolff and Toniolo, 1995)

The most vulnerable periods for toxic impact of environmental pollutants on human development are the embryonic and foetal stages.(Daston et al., 2004; Selevan et al., 2000; Weiss, 2000) Pregnant and nursing women pass these pollutants to their babies both transplacentally and via lactation, and evaluating the maternal contamination is an indirect measurement of the exposure of the foetus to external contaminants. (Suzuki et al., 2005; Wang et al., 2004) One of the most significant concerns regarding health effects is the harmful influence of PCBs and PCDDs/PCDFs on future generations, stemming from prenatal and/or postnatal exposure.(Konishi et al., 2009; Wang et al., 2004)

Furthermore, women and children are most vulnerable as they bear a disproportionate burden from environmental pollution and degradation. Hence they are exposed to particulate pollution and other environmental toxins in the air, food and water of rural and urban areas. (Cutter, 1995)

In most of the developing countries including Brazil, the rural population is most affected by exposure to insecticides, fungicides and herbicides, as agriculture is a main source of employment, particularly for women.( Moses et al.,1993; Soares and Porto, 2007; Reports of acute toxic exposure to POPs in 
adults, including a few studies on the reproductive effects of pesticides, have been published in Brazil.(Baker et al.,1978; Igbedioh, 1991; Loevinsohn 1987) Additionally, human data obtained by the Unified Health System's database ("DATASUS"), from 1994 to 2004 in the State of Paraná, Brazil, showed a significant decline in male birth rates in municipalities with high levels of pesticides present in the environment.(Gibson and Koifman, 2008)

\subsection{Brazilian agriculture and the use of agrotoxics}

Pesticides have been widely used in agriculture in Brazil since the 1940s. In the 1950s, organophosphate insecticides were introduced in Brazil to substitute organochlorines that were found to have a long environmental persistence.(Sato et al.,2006) According to the Brazilian Agricultural and Livestock Confederation Report of 2008, agribusiness generated $28 \%$ of the Brazilian GNP (Gross National Product), and in 2003, sales of agrotoxics amounted to 375000 tons of commercial product, which is equivalent to 182400 tons of the active ingredient. (Confederation, 2008) Over the years, the use of agrotoxic substances has increased significantly, and currently Brazil is considered to be one of the biggest consumers worldwide, with sales increasing by $160 \%$ between 1991 and 1998 .

Historically, DDT was manufactured in Brazil between 1962 and 1982, with the total production estimated to be about 73481 tons. In 1985 DDT was banned for agricultural use, and in 1998 it was banned for public health use. In 2009 all DDT products still in circulation were removed and currently DDT is prohibited for production, trade and use.(Brazil, 2009) In contrast, since 1995 Brazil has markedly increased the use of organophosphates with the average annual use between 1998 - 2005 being 60935 tons. (Sato et al., 2006)

It is estimated that in the agricultural sector, about 12 millions rural employees are exposed daily to toxic substances. Although personal protective equipment (PPE) is provided, in many cases employees ignore and/or fail to use 
the PPE correctly, leading to poor compliance. As a result, farm workers are considered to be the most exposed population and the main target for adverse effects.(Oliveira-Silva et al., 2001)

The National Agency of Sanitary Vigilance (ANVISA) in Brazil reported in 2002 that because of Brazil's very high usage of agrotoxics, new legislation was implemented. The reverse logistic legislation compels the producers to collect the packaging of products after they have been used, thus preventing inappropriate disposal of agrotoxics that could result in secondary pollution to rivers and soils. This legislation has an important public and environmental health benefit, if it is applied strictly. (Sato et al., 2006)

In response to the lack of comprehensive data on levels of persistent toxic substances (PTS) in pregnant women from Brazil, a pilot project was designed and carried out by the Univ. Estadual Paulista (UNESP) and the University of Tromsø, Norway, under the auspices of the Arctic Monitoring and Assessment Programme (AMAP) during the period 2007-2008. The study measured levels of selected toxic metals and POPs in maternal whole blood of total number of 155 delivering women. This paper reports on the levels of $\mathrm{PCBs}$ congeners and pesticides (DDTs metabolites, $\alpha-\mathrm{HCH}, \beta-\mathrm{HCH}, \gamma-\mathrm{HCH}, \mathrm{HCB}, t$-chlordane, $c$ chlordane, oxy-chlordane, $t$-nonachlor and $c$-nonachlor) in maternal whole blood of delivering women in seven selected regions of São Paulo State in Brazil. The seven study sites differ in their degree of environmental pollution and were selected for this very reason.

Socio-economic and self reported health and lifestyle factors as well as birth outcomes, are also reported. Based on these findings, a longitudinal main study will be designed to investigate sources of exposure and reproductive outcomes in various parts of Brazil. 


\section{Materials and Methods}

\subsection{Study sites and population}

Agricultural and industrial activities were considered when choosing the sites. The study took place in seven sites of São Paulo State situated in the southeastern region of Brazil (Figure 1). São Paulo State is the most developed state in Brazil with an area of $248808 \mathrm{~km}^{2}$ and a population of approximately 40 million inhabitants.

Two rural sites (Botucatu and Ribeirão Preto), one industrial site (Campinas), one coastal site (Santos) and three metropolitan urban sites (Univ. Federal of São Paulo (UNIFESP), Vila Nova Cachoeirinha and Hospital and Maternity Leonor Mendes de Barros, HMMLMB) were selected. Two rural sites are located inland of São Paulo State (Botucatu and Ribeirão Preto) and are approximately $230 \mathrm{~km}$ from São Paulo city. Their economy is based mainly on agriculture, derived mostly from sugarcane, and the population is exposed to sugarcane activities, mainly burning and pesticide application. Three urban sites were selected in different areas of São Paulo city (UNIFESP, HMMLMB, Vila Nova Cachoeirinha). The urban site of São Paulo city was selected because of its large population, high-density living, heavy traffic volume and excessive air pollution. The coastal site, the city of Santos situated on the Atlantic Ocean and approximately $70 \mathrm{~km}$ from São Paulo was selected mainly because its estuary is polluted by industrial and urban sewage discharges and by harbour activities. Additionally, it is an endemic dengue area where the spraying of insecticides was reintroduced in 2000. The industrial site (Campinas) is a large city with heavy traffic and is home to a variety of industries, including petrochemicals.

Furthermore, a national and international network was established, with the national group consisting of seven centres and a national coordinator from the bio repository centre (Botucatu). 
This pilot study had a total of 155 participants; All study sites have public maternal hospitals. Enrollment criteria for this project included women who were admitted to the delivery rooms at seven maternity hospitals during 2007 and 2008 and had resided in the specific study site for at least 1 year prior to the pregnancy but duration at the present address was also recorded. Women who volunteered to participate in the study signed an informed consent form and agreed to donate blood and answer a socio-economic questionnaire and allow access to their post-delivery records. Pesticide exposure was defined as a history of exposure to spraying during pregnancy. In urban areas, domestic use of insecticides was assumed to be a mode of exposure, whereas in rural area agricultural sites, spraying was thought to be the predominant source of exposure. The questionnaire was based on prior studies of women and newborns, translated and adapted for the Brazilian population.(Sandanger et al.,2007)

\subsection{Sampling procedures}

From each mother, non-fasting samples of venous blood were collected within one day post-partum, employing standard Vacutainer tubes containing heparin as anticoagulant and using the sterile Vacutainer disposable system. The samples were stored at $-20^{\circ} \mathrm{C}$ and shipped in a frozen state to the University of Troms $\varnothing$, in Norway, for analyses.

\subsection{Sample preparation}

The whole blood samples were extracted according to a liquid-liquid extraction method published by Sandanger et al.(Sandanger et al., 2003) In short, an internal standard mixture (containing fifteen 13C labelled PCBs and eleven of the chlorinated pesticides) was added to $2 \mathrm{ml}$ of blood before mixing with $2 \mathrm{ml}$ of ethanol and $2 \mathrm{ml}$ of deionised water saturated with ammonium sulfate, and extracted twice with $10 \mathrm{ml}$ of $\mathrm{n}$-hexane in a small glass tube. The volume of the 
extract was reduced to $0.5 \mathrm{ml}$ using the Rapidvap (Labconco Corp., Kansas City, $\mathrm{MO})$, before clean up and fractionation on a florisil column as described previously (Sandanger et al., 2007).

\subsection{Instrumentation: Gas chromatography}

Whole blood samples were analysed for the following compounds; PCBs (99, $101,118,138,153,156,163,170,180,183,187,194)$, and p,p'- DDT, pp'DDE, $\alpha-\mathrm{HCH}, \beta-\mathrm{HCH}, \gamma-\mathrm{HCH}, \mathrm{HCB}, t$-chlordane, $c$-chlordane, oxy-chlordane, $t$ nonachlor and $c$-nonachlor at the Norwegian Institute for Air Research (NILU) laboratory in the Polar Environmental Center, Troms $\varnothing$, Norway.

The extracts were analysed using an Agilent 7890A gas chromatograph (GC) equipped with a 5975c mass spectrometer (Agilent Technologies, Böblingen, Germany). The GC was fitted with a $30 \mathrm{~m}$ DB5-MS column $(0.25 \mathrm{~mm}$ id and 0.25 $\mu \mathrm{m}$ film thickness; J\&W, Folsom, USA). Helium (6.0 quality, Hydrogas, Porsgrunn, Norway) was used as carrier gas at a flow rate of $1 \mathrm{ml} / \mathrm{min}$. Two $\mu \mathrm{L}$ of the sample extract were injected in splitless mode using a split / splitless injector (injector and autosampler - Agilent 7683 Series, Agilent Technologies, Böblingen, Germany). The GC temperature programme for chromatographic separation was done using an initial temperature of $70^{\circ} \mathrm{C}$ with a hold time of $2 \mathrm{~min}$, the temperature was then ramped at $15^{\circ} \mathrm{C} / \mathrm{min}$ to $180^{\circ} \mathrm{C}$, followed by a temperature ramp of $5^{\circ} \mathrm{C} / \mathrm{min}$ to $280^{\circ} \mathrm{C}$ with a hold time of $5 \mathrm{~min}$. The electron capture negative ionisation $(\mathrm{ECNI})$ mode was used for identification and quantification of the pesticides, while the electron impact (EI) mode was used for determination

and quantification of PCBs and DDTs. In both cases, the selected ion monitoring (SIM) mode was used and the different compounds were identified from their SIM masses, isotopic ratio and retention times. Peaks with differences in isotopic ratio greater than $20 \%$, compared with the quantification standard, were rejected and not quantified. For every 10 samples, a blank was analysed to assess laboratory-derived (i.e., inadvertent) sample contamination. A standard reference 
material from the AMAP ringtests was also included in each 10 sample batch. The LODs were calculated using the signal to noise calculations in real samples.

Lipids were determined gravimetrically by evaporating the extract to dryness and weighing the extract when stable weight was achieved.

\subsection{Quality assurance and control}

NILU participates in the AMAP Human Health Ringtest for plasma samples. The laboratory has participated in the programme from the outset and has performed well to date. Ringtest performance and the regular analysis of certified reference materials clearly indicate that the uncertainty associated with the calculated concentrations is well within $+/-20 \%$, which is considered the best performance, according to the AMAP ringtest protocol. The high number of labelled internal standards also ensures the quality of the analysis.

As for the determination of lipids, the enzymatic method is considered to be the more precise measurement. In this study only whole blood samples were available; hence, lipids had to be determined gravimetrically. As shown in the work by Sandanger et al. 2004, the gravimetric determination is expected to yield results that are 10-20\% lower than the enzymatic method.(Sandanger et al., 2004) This needs to be taken into consideration when lipid weight levels are being compared to other data.

\subsection{Statistical analyses}

Descriptive statistics, ANOVA one way was applied to compare the differences between sites followed by Tukey test for multiple comparisons (adjusted for age and parity). Due to a non-normal data distribution, analytical results for all compounds were log transformed before statistical analysis of lipid adjusted values. All levels below the LOD were set to half LOD, and were included as such in the statistical analyses. 
Only compounds with levels above LOD in more than $70 \%$ of samples (PCB 118 , PCB138, PCB 153, p,p'-DDE, $\beta$-HCH, $y-H C H, H C B$, oxy-chlordane, $t$-nonachlor were statistically evaluated further. The criteria of significance was set to $P=0.05$. The STATA software package, version 10.0 was used to perform the statistical calculations. (Stata10, 2007)

\subsection{Ethical considerations}

The study protocol was submitted and fully approval by the Brazilian National Research Ethical Council (CONEP-Brazil; protocol number 12388). The study subjects were women admitted for delivery at institutional hospitals in each of the seven study sites. Potential participants received plain-language information about the study and those who agreed to participate signed a written consent form, which stated that participation was voluntary, confidentiality was assured and participants could withdraw from the study at any time. Subjects were also informed that if results where cause for concern, they would be referred to an appropriate care medical facility. Ninety eight percent of potential study participants approached agreed to participate.

\section{Results}

The study took place during 2007 and 2008, and the analytical measurements were completed at the end of 2009. In the tables that follow, study sites are referred to according to their characteristics, and presented in a particular order: Rural 1 (Botucatu); Rural 2 (Ribeirão Preto); São Paulo metropolis is divided into: Urban 1 (UNIFESP), Urban 2 (Vila Nova Cachoeirinha), Urban 3 (HMMLMB); Industrial (Campinas) and Coastal (Santos).

\subsection{Socio-economic, demographic and lifestyle characteristics}

Socio-economic, demographic and lifestyle characteristics for participants at each study site are summarised in Table 1 . The subsets did not differ from the 
overall cohort in terms of demographic variables. The majority of participants were married or lived with their partners, owned their own homes (median 3 rooms / house) and reported a median monthly income of about US\$ 480.The majority of the subjects classified themselves as being from the Caucasian race. Less than half of the women were employed. The pesticides used at home varied according to the site, the most prevalent usage being in the three urban sites (São Paulo city). The domestic use of pesticides (yes / no) was reported by 84 women, representing $53 \%$ of the study participants. Commercially available Baygon (containing mainly Pyrethroids) was commonly used. Use of pesticides outdoors was most prevalent in both rural sites with $50 \%$ of participants reporting to grow own vegetables. Almost $44 \%$ of the women reported that at least one person smoked at home. The majority (90\%) of the participants reported to be in a good state of health; the study subjects who reported being most satisfied with their living environment were from the industrial site.

\subsection{Maternal age, weight, height, parity and neonatal outcomes by site}

Table 2 reports on maternal age, weight, height, parity and neonatal outcomes by site. The mean maternal age of all delivering women was 26.3 years; the youngest delivering woman was 14 years old and the oldest was 43 years old. The parity ranged from 1 to 6 with a median of 2 . Overall $36 \%$ of deliveries were by Caesarian section. The mean maternal weight on the last prenatal care visit was $74.5 \mathrm{~kg}$, varying from 45 to $114 \mathrm{~kg}$. The mean maternal height was $1.59 \mathrm{~m}$, ranging from $1.45 \mathrm{~m}$ to $1.73 \mathrm{~m}$.

Overall birth weight for newborns ranged from 995 to $4460 \mathrm{~g}$, and length from 29 to $58 \mathrm{~cm}$. The mean gestational age at delivery was 38.2 weeks. Gender ratio differed between sites, ranging from 32 to $71 \%$ frequency for girls.

\subsection{Maternal blood levels of contaminants}


To allow for comparisons with non lipid adjusted published data, the concentrations and range of the different compounds measured in maternal whole blood $(\mathrm{pg} / \mathrm{ml})$, unadjusted for lipids are summarised in Table 3. The overall median, first and third quartiles, LOD value for each compound and the percentage of detected cases higher than LOD are presented. Of the 23 compounds measured, 9 (39\%) showed concentrations above LOD of the instrument in more than $70 \%$ of the samples.

Table 4 reports comparisons of log transformed results between sites for compounds with concentration above LOD in more than $70 \%$ of blood samples and adjusted for age and parity. Only nine compounds met this criteria and these are PCB 118, PCB 138, PCB 153, p, p'-DDE, $\beta-\mathrm{HCH}, \gamma-\mathrm{HCH}, \mathrm{HCB}$, oxychlordane, $t$-nonachlor.

The mean concentration of PCB 118 ranged from $2.55 \mathrm{ng} / \mathrm{g}$ lipids in Coastal to $4.92 \mathrm{ng} / \mathrm{g}$ lipids in industrial sites and showed statistical significance of $\mathrm{p}=0.004$ between industrial and Rural 2 and Coastal sites. The differences for PCB 138 were not significant and highest concentrations were measured in Urban 3 site (4.27 ng/g lipids). PCB 153 levels ranged from $3.93 \mathrm{ng} / \mathrm{g}$ lipids (Urban 1) to $7.2 \mathrm{ng} / \mathrm{g}$ lipids in industrial site with no significant differences between sites.

$p, p^{\prime}-\mathrm{DDE}$ was present in $100 \%$ of samples, with the highest concentration found in the Urban 3 site (645ng/g lipids), followed by the industrial site $(417 \mathrm{ng} / \mathrm{g}$ lipids) and the lowest concentration was found in coastal site (126 $\mathrm{ng} / \mathrm{g}$ lipids), differences being significant $(p=0.02)$. The highest levels of $p, p^{\prime}-D D E$ found in women from the Urban 3 site might be attributed to the fact that they resided in this region for 11.2 (SD 9.9) years. The fact that $p p^{\prime}$-DDT was detected in only $20 \%$ of samples indicates that exposure to DDT took place in the past. 
$\mathrm{B}-\mathrm{HCH}$ highest concentration was measured in the Rural 1 site $(37.9 \mathrm{ng} / \mathrm{g}$ lipids) followed by the Urban 3 site ( $29.3 \mathrm{ng} / \mathrm{g}$ lipids). The difference between the sites was highly significant $(p<0.0001)$.

The highest mean concentration of $\mathrm{y}-\mathrm{HCH}$ and $\mathrm{HCB}$ was measured in the Rural 1 and industrial sites ( $1 \mathrm{ng} / \mathrm{g}$ lipids and $10 \mathrm{ng} / \mathrm{g}$ lipids respectively) but only $\mathrm{y}-\mathrm{HCH}$ differed between sites $(p=0.03)$.

Oxy-chlordane was present in all of the samples, with the highest concentration found in the Rural 2 site ( $5.6 \mathrm{ng} / \mathrm{g}$ lipids) followed by the Rural 1 site (3.04 ng/g lipids). The level found in the Rural 2 site was significantly higher than all other sites $(p<0.0001)$.

$T$-nonachlor was present in $99 \%$ of the samples, with the highest concentration found in the Rural 2 site $(2.0 \mathrm{ng} / \mathrm{g}$ lipids) followed by the Rural 1 site (1.42 $\mathrm{ng} / \mathrm{g}$ lipids). The level found in the Rural 2 site was significantly higher than all other sites, except Urban 2 site $(p<0.001)$.

Overall, concentrations of PCB138, PCB153, PCB180, pp'-DDE, B-HCH, oxy-chlordane and $t$-nonachlor were found to be significantly higher in women of 30 years of age and above. The levels of PCB118, PCB138, PCB153, $\alpha-\mathrm{HCH}, \beta$ $-\mathrm{HCH}$ and $\mathrm{c}$-chlordane were found to be highest in primiparous women and also statistically significant.

\section{Discussion and conclusions}

Limited information is available on the prenatal exposure to POPs especially in the populations residing in the southern hemisphere. To assess possible exposure of neonates to these compounds, our study quantified the levels of selected POPs in whole blood of delivering women from seven selected regions 
of São Paulo State, Brazil and has shown that these contaminants are present in women residing in the São Paulo State of Brazil.

Thus, the study detected 12 PCB congeners in the maternal blood but only three namely PCB 118, PCB 138 and PCB 153 congeners were dominant (e.g. present in more than $70 \%$ samples). We may speculate that the limited number of congeners observed might be a result of the introduction and implementation of Brazilian PCB legislation in 1981which prohibits the manufacturing, marketing, use and disposal of PCBs in Brazil.(Penteado and Vaz, 2001) The study by Klantzi et al, 2009 that measured PCBs in human breast adipose tissues in 20042005 in Porto Alegre, the capital of the Rio de Grande do Sul state of Brazil also detected lower levels of this PCB congener if compared with results of 1999. (Erdmann et al.,1999) Levels of PCB congeners found in the current study are comparable to those measured in the general population in other nonindustrialised developing countries such as Tanzania and India, but lower than those recently reported from Guinea-Bissau and from industrialised countries in the North. (Anda et al.,2008; Linderholm et al.,2010; Todaka et al., 2010; Weiss et al.,2006) Interestingly, PCB levels in Brazilian delivering women were higher than those recently reported in the plasma of delivering women in South Africa and Vietnam. (Hansen et al.,2009; Röllin et al., 2009) They were however lower than those reported by Van Oostdam et al, 2004 in comparable populations residing in Canada, the Netherland and Spain. The imbalanced distribution of this large group of 209 PCB congeners - all of which have different physiochemical properties, different ranges of persistence and biological activity; - is important information that can possibly contribute to the global debate. (Birnbaum and Staskal-Wikoff, 2010)

The environmentally persistent $p, p^{\prime}$-DDE metabolite was detected in $100 \%$ of maternal blood samples in our study and $p, p^{\prime}$-DDT metabolite was detected in only $20 \%$ of the samples both at relatively low concentrations which is an indication that no recent exposure to DDT took place. Another study performed 
in 2003 in Rio de Janeiro, Brazil, found p,p'-DDE in the breast milk of $97 \%$ of participating breastfeeding mothers; with concentrations ranging from 0.16 to 8 $\mathrm{ppb}$. The results from the present study in São Paulo State indicate that DDT contaminations are comparable to those in Rio de Janeiro State. (Sarcinelli et al.,2003) As expected, the concentrations of $p p^{\prime}$-DDE found in delivering women from São Paulo State are lower than those found in Mexican and South African delivering women residing in areas where DDT is used to control malaria vector. In contrast, the levels of $p p^{\prime}-\mathrm{DDE}$ were found to be much higher in delivering women in our study if compared with recent similar studies performed in Vietnam and elsewhere.(Hansen et al., 2009; Röllin et al., 2009; Waliszewski et al.,2000)

Due to the extensive agricultural activities in São Paulo State, our study found higher levels of pesticides in blood of delivering women mostly in rural areas. It is thought that sources of exposure to these pollutants may be both from recent and past activities. It is common practice in Brazil to use municipal solid waste as compost to enrich the soil for agricultural use; it is very possible that this practice has led to overall increase in levels of pollutants in soil, groundwater and in plants, consequently contributing to human exposure. (Lourencetti et al., 2007)

This study also confirmed that the body burden of selected POPs increases with age and decreases with parity in accordance with other studies. (Grimvall et al., 1997; O'Grady Milbrath et al.,2009; Skaare and Polder 1990) It is of concern that chronic exposure to low levels of POPs that can lead to cumulative adverse health effects in exposed populations over an extended period of time and ultimately affecting reproductive health outcomes.(Lee et al., 2006)

The recent Global Monitoring Report of 2009 indicates that there is a gap in knowledge on levels and trends of POPs in ecosystems as well as in humans in most developing countries and in countries in transition. In addition different climatic conditions in countries situated in the southern hemisphere promote an 
increase in the use of pesticides for pests and vector control. Use of outdated industrial processes combined with uncontrolled disposal of hazardous chemicals and wastes is also of concern. (UNEP, 2009)

In conclusion, our study quantified pre natal exposure to multiple organic contaminants and contributed to the knowledge of possible exposures to POPs in São Paulo State, Brazil. Although sample size was limited in this pilot stage of the investigation; it produced enough evidence for future studies in Brazil. The strength of our investigation lies in the usage of standardised methods of sample and data collection and comparable analytical methodology.

To the best of our knowledge, this pilot study is the first Brazilian investigation that concurrently measured a wide spectrum of POPs in whole blood of delivering women, in selected areas of São Paulo State, Brazil. The findings may be useful as baseline data for future investigations, particularly regarding temporal trends of exposure to POPs in São Paulo State. As there is no similar data for other parts of Brazil, it is recommended that the study be extended to other regions within Brazil and southern hemisphere, thus contributing to the debate on the climate change, contaminants and human health.

Furthermore, the study involved a multidisciplinary international team of research scientists and laid foundation for building the research capacity in Brazil that will be used in future collaborative investigations. 


\section{Acknowledgements}

The authors are indebted to the University of Tromsø, Norway; the University of Aarhus, Denmark; the Arctic Monitoring and Assessment Programme (AMAP), Oslo, Norway; and the Nordic Council of Ministers, Copenhagen, Denmark for the financial support of this study.

We deeply thank all the participants who kindly participated in this survey and staff at the seven study sites, who enrolled patients for this study. We also thank Maria Aparecida Mourão Brazil, Adriano Dias, and Hélio Rubens Nunes from GAP-Research Support Center, for statistical support, and Linda Hansen and Therese Nøst from the National Institute of Air Research (NILU) for their analytical expertise. Authors thank Claudina Nogueira from the National Institute for Occupational Health, Johannesburg, South Africa for her input into final manuscript.

The first author (C. Rudge) is a recipient of a doctoral PDEE fellowship from the Brazilian Federal Agency for Graduate Studies (CAPES, Ministry of Education). 


\section{References}

Anda, E.E.; Nieboer, E.; Voitov, A.V.; Kovalenko, A.A.; Lapina, Y.M.; Voitova, E.A., et al. Implementation, quality control and selected pregnancy outcomes of the Murmansk County Birth Registry in Russia. Int J Circumpolar Health. 2008;67:318-334.

Baker, E.L., Jr.; Warren, M.; Zack, M.; Dobbin, R.D.; Miles, J.W.; Miller, S., et al. Epidemic malathion poisoning in Pakistan malaria workers. Lancet.1978; 1:31-34.

Birnbaum, L.S. and Staskal-Wikoff, D.S. 5th international PCB workshop - Summary and implications. Environ Int (2010), doi:10.1016/j.envint.2010.06.011

Brazil, F. Lei No 11.936. Lei 11936/09 | Lei No 11936, de 2009

Brouwer, A.; Morse, D.C.; Lans, M.C.; Schuur, A.G.; Murk, A.J.; Klasson-Wehler, E., et al. Interactions of persistent environmental organohalogens with the thyroid hormone system: mechanisms and possible consequences for animal and human health. Toxicol Ind Health. 1998;14:59-84.

Confederation, N.A. Brazilian Agricultural and Livestock Confederation. In: Ministery A, ed; 2008

Cutter, S.L. The forgotten casualties: women, children, and environmental change. Glob Environ Change. 1995;5:181-194.

Daston, G.; Faustman, E.; Ginsberg, G.; Fenner-Crisp, P.; Olin, S.; Sonawane, B., et al. A framework for assessing risks to children from exposure to environmental agents. Environ Health Perspect. 2004;112:238-256.

Erdmann, C.A., Petreas, M.X.; Cafetti, M.; Barbosa, F.S.;Goth-Goldstein, R. Comparison of organochlorine chemical body burdens of female breast cancer cases with cancer free women in Rio Grande do Sul, Brazil - Pilot study. LBNL report \# $43755 ; 1999$

Gibson, G.; Koifman, S. [Agricultural toxic use and temporal distribution of male birth rate in the state of Parana, Brazil]. Rev Panam Salud Publica. 2008;24:240-247.

Grimvall, E.; Rylander, L.; Nilsson-Ehle, P.; Nilsson, U.; Stromberg, U.; Hagmar, L., et al. Monitoring of polychlorinated biphenyls in human blood plasma: methodological developments and influence of age, lactation, and fish consumption. Arch Environ Contam Toxicol. 1997;32:329-336.

Hansen, S.; Odland, J.O.; Phi, D.T.; Nieboer, E.; Sandanger, T.M. Maternal levels of organochlorines in two communities in southern Vietnam. Sci Total Environ. 2009;408:225-232.

Igbedioh, S.O. Effects of agricultural pesticides on humans, animals, and higher plants in developing countries. Arch Environ Health. 1991;46:218-224.

Kalantzi,O.I.; Brown, F.R.;Caleffi, M.; Goth-Golstein, R.; Petres, M. Polybrominated diphenyl ethers and polychlorinated biphenyls in human breast adipose samples from Brazil. Environ International 2009;35:113-117.

Konishi, K.; Sasaki, S.; Kato, S.; Ban, S.; Washino, N.; Kajiwara, J., et al. Prenatal exposure to PCDDs/PCDFs and dioxin-like PCBs in relation to birth weight. Environ Res. 2009;109:906-913.

Lee, D.H.; Lee, I.K.; Song, K.; Steffes, M.; Toscano, W.; Baker, B.A., et al. A strong dose-response relation between serum concentrations of persistent organic 
pollutants and diabetes: results from the National Health and Examination Survey 1999-2002. Diabetes Care. 2006;29:1638-1644.

Loevinsohn, M.E. Insecticide use and increased mortality in rural Central Luzon, Philippines. Lancet. 1987;1:1359-1362.

Lourencetti, C.; Favoreto, R.; Marchi, M.R.; Ribeiro, M.L. Residues of organochlorine pesticides and PCBs in some Brazilian municipal solid waste compost. J Environ Sci Health B. 2007;42:697-705.

Moses, M.; Johnson, E.S.; Anger, W.K.; Burse, V.W.; Horstman, S.W.; Jackson, R.J., et al. Environmental equity and pesticide exposure. Toxicol Ind Health. 1993;9:913959.

O’Grady Milbrath,M; Wenger,Y; Chang,Ch-W; Emond,C; Garabrant,D; Gillespie, BW; and Jolliet O. Apparent Half-Lives of Dioxins, Furans, and Polychlorinated Biphenyls as a Function of Age, Body Fat, Smoking Status, and Breast-Feeding. Environ Health Perspect. 2009;17(3):417-425.

Oliveira-Silva, J.J.; Alves, S.R.; Meyer, A.; Perez, F.; Sarcinelli, P.N.; da Costa Mattos, R.C., et al. [Influence of socioeconomic factors on the pesticides poisoning, Brazil]. Rev Saude Publica. 2001;35:130-135.

Patandin, S.; Lanting, C.I.; Mulder, P.G.; Boersma, E.R.; Sauer, P.J.; Weisglas-Kuperus, N. Effects of environmental exposure to polychlorinated biphenyls and dioxins on cognitive abilities in Dutch children at 42 months of age. J Pediatr. 1999;134:3341.

Penteado, J.; Vaz, J. The legacy of the polychlorinated biphenyls (PCBs). Quimica Nova. 2001;24:390-398.

Porta, M.; Puigdomenech, E.; Ballester, F.; Selva, J.; Ribas-Fito, N.; Llop, S., et al. Monitoring concentrations of persistent organic pollutants in the general population: the international experience. Environ Int. 2008;34:546-561.

Ribas-Fito, N.; Sala, M.; Kogevinas, M.; Sunyer, J. Polychlorinated biphenyls (PCBs) and neurological development in children: a systematic review. J Epidemiol Community Health. 2001;55:537-546.

Röllin, H.B.; Sandanger, T.M.; Hansen, L.; Channa, K.; Odland, J.O. Concentration of selected persistent organic pollutants in blood from delivering women in South Africa. Sci Total Environ. 2009;408:146-152.

Sandanger, T.M.; Brustad, M.; Lund, E.; Burkow, I.C. Change in levels of persistent organic pollutants in human plasma after consumption of a traditional northern Norwegian fish dish-molje (cod, cod liver, cod liver oil and hard roe). J Environ Monit.2003; 5:160-165.

Sandanger, T.M.; Dumas, P.; Berger, U.; Burkow, I.C. Analysis of HO-PCBs and PCP in blood plasma from individuals with high PCB exposure living on the Chukotka Peninsula in the Russian Arctic. J Environ Monit. 2004;6:758-765.

Sandanger, T.M.; Sinotte, M.; Dumas, P.; Marchand, M.; Sandau, C.D.; Pereg, D., et al. Plasma concentrations of selected organobromine compounds and polychlorinated biphenyls in postmenopausal women of Quebec, Canada. Environ Health Perspect. 2007;115:1429-1434.

Sarcinelli PN; Periera AC; Mesquita, S.A.; Oliveira-Silva, J.J.; Meyer, A.; Menezes, M.A., et al. Dietary and reproductive determinants of plasma organochlorine levels in pregnant women in Rio de Janeiro. Env Research 2003; 91(3):143-150. 
Sato, G.S.; Carbone, G.T.; Moori, R.G. PRÁTICAS OPERACIONAIS DA LOGÍSTICA REVERSA DE EMBALAGENS DE AGROTÓXICOS. Revista de Gestão Integrada em Saúde do Trabalho e Meio Ambiente. 1; 2006

Selevan, S.G.; Kimmel, C.A.; Mendola, P. Identifying critical windows of exposure for children's health. Environ Health Perspect. 2000;108 Suppl 3:451-455.

Skaare, J.U.; Polder, A. Polychlorinated biphenyls and organochlorine pesticides in milk of Norwegian women during lactation. Arch Environ Contam Toxicol. 1990;19:640-645.

Snedeker, S.M. Pesticides and breast cancer risk: a review of DDT, DDE, and dieldrin. Environ Health Perspect. 2001;109 Suppl 1:35-47.

Soares, W.L.; Porto, M.F. [Agricultural activity and environmental externality: an analysis of the use of pesticides in the Brazilian savannah]. Cien Saude Colet. 12:131-143; 2007

Stata10. Stata Statistical Software: Release 8.0. In: StataCorpLP, ed. College Station TX; 2007

Suzuki, G.; Nakano, M.; Nakano, S. Distribution of PCDDs/PCDFs and Co-PCBs in human maternal blood, cord blood, placenta, milk, and adipose tissue: dioxins showing high toxic equivalency factor accumulate in the placenta. Biosci Biotechnol Biochem. 2005;69:1836-1847.

Todaka, T.; Hirakawa, H.; Kajiwara, J.; Hori, T.; Tobiishi, K.; Yasutake, D., et al. Relationship between the concentrations of polychlorinated dibenzo-p-dioxins, polychlorinated dibenzofurans, and polychlorinated biphenyls in maternal blood and those in breast milk. Chemosphere. 2010;78:185-192.

Tryphonas, H. The impact of PCBs and dioxins on children's health: immunological considerations. Can J Public Health. 1998;89 Suppl 1:S49-52, S54-47.

UNEP, Global Monitoring Report UNEP/POP/COP.4/33. 2009

Van Oostdam,JC; Dewailly,E; Gilman,A; Hansen, JC; Odland, JO; Chashchin, V; Berner, J; Butler-Walker, J; Lagerkvist, BJ; Olafsdottir,K; Soininen, L; Bjerregard, P; Klopov, V, Weber, JP. Circumpolar maternal blood contaminants survey, 19941997 organochlorine compounds. Sci Total Environ.2004;330:55-70.

Waliszewski, S.M.; Aguirre, A.A.; Infanzon, R.M.; Siliceo, J. Partitioning coefficients of organochlorine pesticides between mother blood serum and umbilical blood serum. Bull Environ Contam Toxicol. 2000;65:293-299.

Wang, S.L.; Lin, C.Y.; Guo, Y.L.; Lin, L.Y.; Chou, W.L.; Chang, L.W. Infant exposure to polychlorinated dibenzo-p-dioxins, dibenzofurans and biphenyls (PCDD/Fs, PCBs)--correlation between prenatal and postnatal exposure. Chemosphere. 54:1459-1473; 2004

Weiss, B. Vulnerability of children and the developing brain to neurotoxic hazards. Environ Health Perspect. 2000;108 Suppl 3:375-381.

Weiss, J.M.; Bauer, O.; Bluthgen, A.; Ludwig, A.K.; Vollersen, E.; Kaisi, M., et al. Distribution of persistent organochlorine contaminants in infertile patients from Tanzania and Germany. J Assist Reprod Genet. 2006;23:393-399.

Wolff, M.S.; Toniolo, P.G. Environmental organochlorine exposure as a potential etiologic factor in breast cancer. Environ Health Perspect. 1995;103 Suppl 7:141145. 
Figure 1 Geographical locations of study sites within Brazil (all three urban sites are located in São Paulo city)
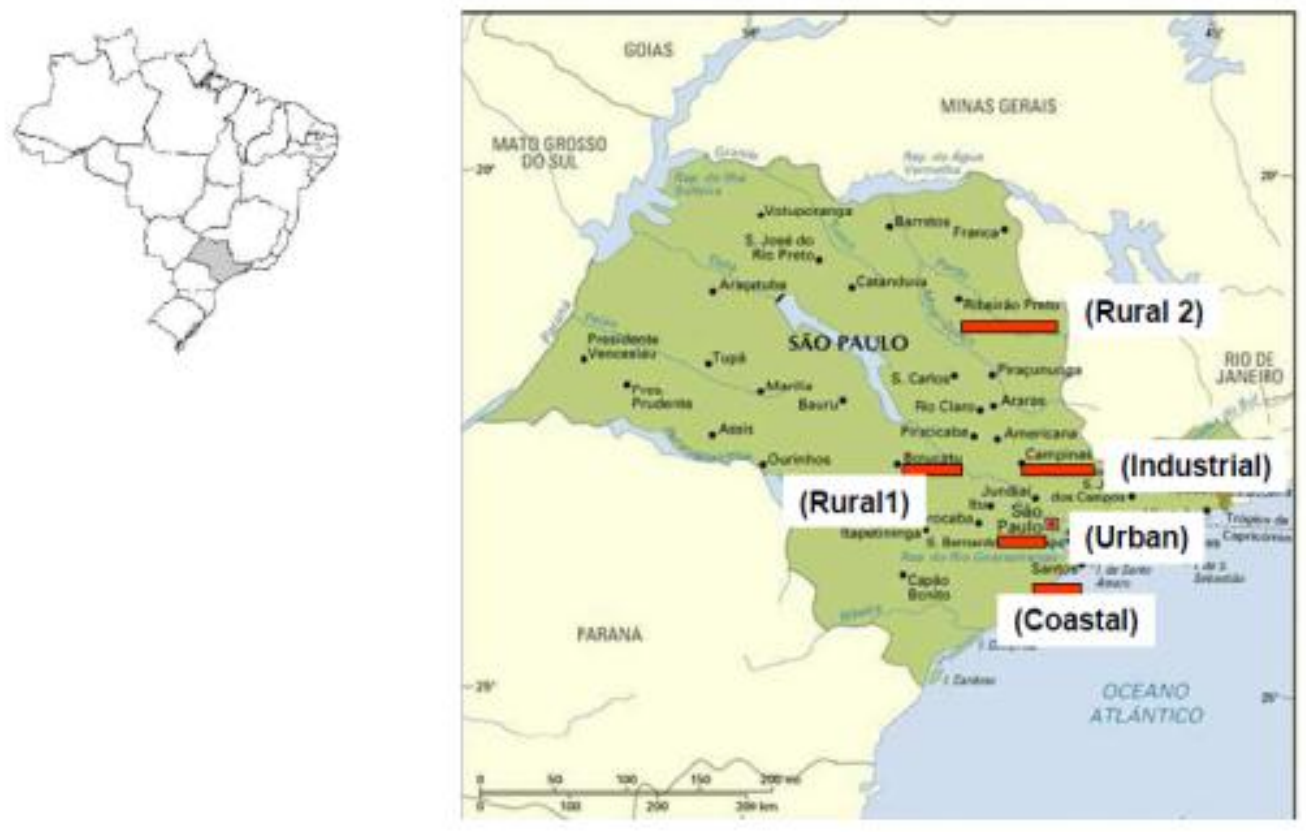
Table 1 Socio-demographic characteristics and life habits of participants by site.

\begin{tabular}{|c|c|c|c|c|c|c|c|c|}
\hline Statistics & $\begin{array}{l}\text { Rural } 1 \\
(\mathrm{n}=36)\end{array}$ & $\begin{array}{l}\text { Rural } 2 \\
(n=19)\end{array}$ & $\begin{array}{l}\text { Urban } 1 \\
(n=20)\end{array}$ & $\begin{array}{l}\text { Urban } 2 \\
(n=20)\end{array}$ & $\begin{array}{l}\text { Urban } 3 \\
(n=20)\end{array}$ & $\begin{array}{l}\text { Industrial } \\
(n=20)\end{array}$ & $\begin{array}{l}\text { Coastal } \\
(n=20)\end{array}$ & $\begin{array}{l}\text { Total } \\
(n=155)\end{array}$ \\
\hline $\begin{array}{l}\text { Population } \\
\text { group (\%) }\end{array}$ & $B=11$ & $B=6$ & $B=10$ & $B=29$ & $B=15$ & $B=0$ & $B=10$ & $B=12$ \\
\hline $\mathrm{B}=$ Black & $\mathrm{C}=31$ & $\mathrm{C}=26$ & $\mathrm{C}=45$ & $\mathrm{C}=33$ & $\mathrm{C}=15$ & $\mathrm{C}=15$ & $\mathrm{C}=20$ & $\mathrm{C}=26$ \\
\hline $\begin{array}{l}\mathrm{C}=\text { Coloured } \\
\mathrm{W}=\text { White }\end{array}$ & $W=58$ & $W=68$ & $W=45$ & $W=38$ & $W=70$ & $W=85$ & $W=70$ & $W=62$ \\
\hline $\begin{array}{l}\text { Do you consider } \\
\text { yourself } \\
\text { healthy }(\% \text { YES })\end{array}$ & 81 & 100 & 65 & 90 & 95 & 100 & 90 & 89 \\
\hline Marital status & & & & & & & & \\
\hline $\begin{array}{l}M=\text { married/ } \\
\text { living together } \\
\text { (\%) }\end{array}$ & 89 & 90 & 85 & 80 & 65 & 65 & 80 & 79 \\
\hline Home & & & & & & & & \\
\hline ownership \% & 63 & 52 & 60 & 62 & 75 & 75 & 65 & 65 \\
\hline Rooms & 3.2 & 3.0 & 2.7 & 2.1 & 2.1 & 2.8 & 2.5 & 2.7 \\
\hline $\begin{array}{l}\text { Income/ } \\
\text { monthly-median } \\
\text { (US\$) }\end{array}$ & 388 & 388 & 555 & 600 & 388 & 417 & 611 & 478 \\
\hline $\begin{array}{l}\text { Employed? \% } \\
\text { Somebody }\end{array}$ & 46 & 16 & 40 & 40 & 20 & 30 & 50 & 35 \\
\hline $\begin{array}{l}\text { smoking } \\
\text { In household\% } \\
\text { Environmental }\end{array}$ & 56 & 53 & 60 & 57 & 40 & 25 & 30 & 46 \\
\hline $\begin{array}{l}\text { pollution in } \\
\text { neighbourhood? } \\
\text { (\%yes) }\end{array}$ & 33 & 74 & 45 & 52 & 55 & 25 & 55 & 48 \\
\hline $\begin{array}{l}\text { Lengths of } \\
\text { residence } \\
\text { (years) }\end{array}$ & $6.5(6.8)$ & $6.3(7.3)$ & $3.3(4)$ & $3.2(4.3)$ & $11.2(9.9)$ & $6.1(7.1)$ & $6.8(8.7)$ & $6.2(6.9)$ \\
\hline
\end{tabular}


Table 2 Maternal age, weight, height, parity and birth outcomes by site

\begin{tabular}{|c|c|c|c|c|c|c|c|c|}
\hline Statistics & $\begin{array}{l}\text { Rural } 1 \\
(n=36)\end{array}$ & $\begin{array}{l}\text { Rural } 2 \\
(n=19)\end{array}$ & $\begin{array}{l}\text { Urban } 1 \\
(n=20)\end{array}$ & $\begin{array}{l}\text { Urban } 2 \\
(n=20)\end{array}$ & $\begin{array}{l}\text { Urban } 3 \\
(n=20\end{array}$ & $\begin{array}{l}\text { Industrial } \\
(\mathrm{n}=20)\end{array}$ & $\begin{array}{l}\text { Coastal } \\
(n=20)\end{array}$ & $\begin{array}{l}\text { All } \\
n=155\end{array}$ \\
\hline \multicolumn{9}{|l|}{ Maternal age } \\
\hline \multirow[t]{2}{*}{ mean (SD) } & 29.1 & 24.6 & 29.4 & 22.9 & 25.4 & 24 & 26.1 & 26 \\
\hline & 6.4 & 6.8 & 7.6 & 4.5 & 6.3 & 6.5 & 6.2 & 5.4 \\
\hline \multicolumn{9}{|l|}{ Maternal weight (kg) } \\
\hline \multicolumn{9}{|l|}{ Mean } \\
\hline \multirow[t]{2}{*}{ SD } & 77.3 & 75.4 & 72.6 & 72.8 & 71.8 & 77.5 & 73.9 & 74.5 \\
\hline & 13.6 & 19.5 & 16.1 & 13.6 & 15.6 & 18.1 & 14.2 & 15.8 \\
\hline \multicolumn{9}{|l|}{ Maternal height (m) } \\
\hline Mean & 1.60 & 1.60 & 1.62 & 1.60 & 1.63 & 1.58 & 1.62 & 1.60 \\
\hline SD & 0.07 & 0.08 & 0.06 & 0.07 & 0.07 & 0.11 & 0.08 & 0.08 \\
\hline Parity median (range) & $2(1-9)$ & $2(1-8)$ & $3(2-4)$ & $2(1-3)$ & $2(1-6)$ & $2(1-3)$ & $2(1-4)$ & $2(1-5)$ \\
\hline \multicolumn{9}{|l|}{ Birth weight (g) } \\
\hline mean & 3021 & 2735 & 3138 & 3259 & 3200 & 2928 & 3069 & 3050 \\
\hline SD & 469 & 740 & 683 & 397 & 339 & 567 & 505 & 529 \\
\hline \multicolumn{9}{|l|}{ Birth length (cm) } \\
\hline Mean & 47 & 47.4 & 47.5 & 48.0 & 48.8 & 47.4 & 47.5 & 47.7 \\
\hline SD & 5.0 & 3.5 & 3.0 & 2.8 & 2.1 & 4.8 & 2.6 & 3.4 \\
\hline \multicolumn{9}{|l|}{ Head circumference $(\mathrm{cm})$} \\
\hline Mean & 35.0 & 33.9 & 34.2 & 35.1 & 34.3 & 34.9 & 34.5 & 34.6 \\
\hline SD & 3.6 & 2.3 & 1.6 & 1.4 & 1.3 & 2.8 & 1.6 & 2.4 \\
\hline \multicolumn{9}{|l|}{ Gestational age (w) } \\
\hline mean & 38.3 & 37.0 & 38.0 & 39.2 & 38.6 & 37.8 & 38.2 & 38.2 \\
\hline SD & 2.1 & 3.9 & 1.6 & 1.4 & 1.5 & 2.2 & 2.1 & 2.1 \\
\hline Gender: girls (\%) & 36.1 & 31.6 & 55 & 71 & 31.5 & 65 & 60 & 50 \\
\hline Caesarean section (\%) & 39 & 32 & 50 & 25 & 10 & 50 & 45 & 36 \\
\hline
\end{tabular}


Table 3: Overall levels of measured POPs in maternal whole blood at delivery $(\mathrm{pg} / \mathrm{ml})$ for all samples

\begin{tabular}{|c|c|c|c|c|c|c|c|c|}
\hline Compounds & $\begin{array}{l}\text { Overall } \\
\text { Median } \\
\text { (all } \\
\text { samples) }\end{array}$ & $\begin{array}{l}\text { Overall } \\
1^{\text {st }} \\
\text { quartile } \\
\text { (all } \\
\text { samples) }\end{array}$ & $\begin{array}{l}\text { Overall } \\
\text { 3rd } \\
\text { quartile } \\
\text { (all } \\
\text { samples) }\end{array}$ & $\begin{array}{l}\text { Overall } \\
\text { Median } \\
\text { (>LOD) }\end{array}$ & $\begin{array}{l}\text { Overall } \\
1^{\text {st }} \\
\text { quartile } \\
\text { (>LOD) }\end{array}$ & $\begin{array}{l}\text { Overall } \\
\text { 3rd } \\
\text { quartile } \\
\text { (>LOD) }\end{array}$ & LOD & $\begin{array}{l}\% \\
\text { detected } \\
>\text { LOD }^{*}\end{array}$ \\
\hline PCB 99 & 4.46 & 2.32 & 8.25 & 14.96 & 14.27 & 17.48 & 11.91 & 10.9 \\
\hline PCB 101 & 6.01 & 3.90 & 9.51 & 14.33 & 12.81 & 16.71 & 11.90 & 19.1 \\
\hline PCB118 & 14.93 & 10.13 & 19.31 & 16.36 & 13.47 & 21.00 & 9.5 & 79.6 \\
\hline PCB138 & 12.83 & 9.55 & 20.35 & 15.77 & 12.11 & 22.88 & 9.67 & 76.2 \\
\hline PCB163 & 3.38 & 1.94 & 5.15 & 12.10 & 9.54 & 14.31 & 9.06 & 11.5 \\
\hline PCB153 & 17.74 & 112.08 & 28.33 & 20.41 & 15.19 & 33.10 & 11.16 & 83.7 \\
\hline PCB156 & 3.12 & 1.87 & 4.63 & & & & 41.07 & 0 \\
\hline PCB170 & 6.03 & 2.89 & 9.30 & 15.96 & 14.75 & 20.81 & 12.18 & 16.3 \\
\hline PCB 180 & 14.19 & 8.93 & 20.14 & 19.58 & 15.68 & 24.60 & 11.03 & 62.6 \\
\hline PCB187 & 4.10 & 2.04 & 7.83 & 13.77 & 12.09 & 18.23 & 10.81 & 12.9 \\
\hline PCB183 & 1.23 & 0.84 & 2.59 & 5.76 & 5.76 & 5.76 & 4.96 & 2.70 \\
\hline PCB194 & 1.86 & 1.22 & 2.24 & & & & 5.00 & 0 \\
\hline$p, p^{\prime}-D D E$ & 280.14 & 113.12 & 860.24 & 280.14 & 113.12 & 860.24 & 11.30 & 100 \\
\hline$p, p-D D T$ & 17.64 & 10.99 & 35.65 & 85.19 & 65.96 & 228.48 & 41.36 & 20.3 \\
\hline$\alpha-\mathrm{HCH}$ & 1.0 & 0.63 & 1.62 & 3.40 & 3.15 & 7.40 & 3.0 & 11.6 \\
\hline$\beta-\mathrm{HCH}$ & 28.64 & 12.32 & 77.42 & 48.70 & 24.23 & 108.09 & 11.0 & 76.9 \\
\hline$\gamma-\mathrm{HCH}$ & 2.8 & 2.15 & 4.11 & 3.20 & 2.55 & 4.49 & 2.0 & 84.4 \\
\hline $\mathrm{HCB}$ & 35.5 & 31.4 & 42.52 & 35.58 & 31.39 & 42.69 & 2.0 & 100 \\
\hline t-chlordane & 0.4 & 0.3 & 0.5 & 0.55 & 0.50 & 0.65 & 0.5 & 41.9 \\
\hline c-chlordane & 0.2 & 0.15 & 0.3 & 0.60 & 0.60 & 0.70 & 0.5 & 7.0 \\
\hline oxy-chlordane & 5.4 & 3.99 & 11.2 & 5.70 & 4.00 & 11.35 & 2.1 & 100 \\
\hline$t$-nonachlor & 2.7 & 1.59 & 5.65 & 2.75 & 1.65 & 5.65 & 0.5 & 99.3 \\
\hline$c$-nonachlor & 0.5 & 0.3 & 0.99 & 0.75 & 0.55 & 1.25 & 0.4 & 57.8 \\
\hline
\end{tabular}

${ }^{*} \mathrm{LOD}=$ limits of detection 
Table 4. Comparison of POPs concentrations in different study sites in maternal blood (ng/g lipids) adjusted for age and parity by ANOVA one-way, followed by Tukey test for multiple comparisons

\begin{tabular}{|c|c|c|c|c|c|c|c|}
\hline \multicolumn{8}{|l|}{ Compound } \\
\hline & $\begin{array}{l}\text { Rural } 1 \\
(\mathrm{n}=36)\end{array}$ & $\begin{array}{l}\text { Rural } 2 \\
(\mathrm{n}=19)\end{array}$ & $\begin{array}{l}\text { Urban } 1 \\
(n=20)\end{array}$ & $\begin{array}{l}\text { Urban } 2 \\
(n=20)\end{array}$ & $\begin{array}{l}\text { Urban } 3 \\
(n=20)\end{array}$ & $\begin{array}{l}\text { Industrial } \\
(n=20)\end{array}$ & $\begin{array}{l}\text { Coastal } \\
(\mathrm{n}=20)\end{array}$ \\
\hline \multirow{4}{*}{$\begin{array}{l}\text { PCB } 118 \\
\text { PCB } 138 \\
\text { PCB } 153 \\
p, p^{\prime}-D D E\end{array}$} & $3.79 \pm 1.77$ & $2.62 \pm 1.95^{*}$ & $3.37 \pm 1.39$ & $3.80 \pm 2.58$ & $3.69 \pm 1.70$ & $4.92 \pm 2.74^{*} \#$ & \multirow{4}{*}{$\begin{array}{l}2.55 \pm 1.59 \# \\
3.82 \pm 1.98 \\
4.65 \pm 2.51 \\
126 \pm 215 \\
\text { *\&@ }\end{array}$} \\
\hline & $3.97 \pm 2.63$ & $4.01 \pm 3.64$ & $2.80 \pm 1.03$ & $2.98 \pm 3.42$ & $4.27 \pm 3.17$ & $3.19 \pm 2.04$ & \\
\hline & $5.23 \pm 3.31$ & $4.61 \pm 3.70$ & $3.93 \pm 2.89$ & $4.48 \pm 4.40$ & $5.89 \pm 4.81$ & $7.20 \pm 5.85$ & \\
\hline & $198 \pm 281$ \#\& & 355×590 \#@ & $164 \pm 358$ * & $145 \pm 326$ *\# & $645 \pm 1347^{*}$ & $417 \pm 1198$ & \\
\hline$\beta \mathrm{HCH}$ & $37.92 \pm 63.23^{*}$ & $9.97 \pm 9.81$ & $3.24 \pm 4.03$ & $9.26 \pm 14.41$ & $29.29 \pm 61.78$ & $28.05 \pm 66.33$ & $5.60 \pm 5.63$ \\
\hline $\mathrm{yHCH}$ & $1.04 \pm 1.40$ & $0.74 \pm 0.34$ & $0.48 \pm 0.37^{*}$ & $0.74 \pm 0.69$ & $0.65 \pm 0.41$ & $1.09 \pm 0.66^{*}$ & $0.73 \pm 0.40$ \\
\hline $\mathrm{HCB}$ & $10.14 \pm 4.45$ & $9.13 \pm 3.75$ & $8.09 \pm 1.79$ & $8.36 \pm 2.29$ & $9.88 \pm 4.29$ & $10.98 \pm 4.41$ & $8.57 \pm 2.75$ \\
\hline oxy-chlordane & $3.04 \pm 2.97$ & $5.60 \pm 4.94^{*}$ & $1.18 \pm 0.66$ & $1.08 \pm 0.56$ & $2.72 \pm 3.61$ & $1.68 \pm 1.22$ & $1.18 \pm 0.44$ \\
\hline$t$ - nonachlor & $1.42 \pm 1.83$ & $2.00 \pm 1.97^{*}$ & $0.49 \pm 0.34^{*}$ & $0.68 \pm 0.86^{*}$ & $1.28 \pm 1.86$ & $0.68 \pm 0.54^{*}$ & $0.69 \pm 0.46^{*}$ \\
\hline
\end{tabular}

*,\#,\&,@ - significant differences by Tukey test at 5\% significance 